\title{
FAKTOR - FAKTOR YANG MEMPENGARUHI PENYELESAIAN SKRIPSI MAHASISWA PENDIDIKAN AKUNTANSI UNIVERSITAS NEGERI YOGYAKARTA ANGKATAN 2011
}

\section{FACTORS AFFECTING THE COMPLETION OF ACCOUNTING EDUCATION STUDENT'S UNDERGRADUATE THESIS BATCH 2011, YOGYAKARTA STATE UNIVERSITY}

\author{
Oleh: \\ Ujang Hartato \\ Prodi Pendidikan Akuntansi Universitas Negeri Yogyakarta \\ ujanghartato@yahoo.com \\ Mimin Nur Aisyah \\ Staf Pengajar Jurusan Pendidikan Akuntansi Universitas Negeri Yogyakarta
}

\begin{abstract}
Abstrak
Tujuan Penelitian ini adalah untuk mengetahui pengaruh Motivasi Lulus Tepat Waktu, Kemampuan Menulis Karya Tulis Ilmiah, Ketersediaan Sumber Belajar, Kualitas Bimbingan Skripsi dan Lingkungan Teman Sebaya baik secara parsial maupun secara bersama-sama terhadap Penyelesaian Tugas Akhir Skripsi. Penelitian ini merupakan penelitian kausal komparatif. Populasi penelitian yaitu semua mahasiswa Pendidikan Akuntansi FE UNY angkatan 2011. Pengumpulan data menggunakan metode kuesioner. Teknik analisis data yang digunakan adalah teknik analisis regresi sederhana dan regresi ganda. Hasil penelitian ini menunjukkan bahwa Motivasi Lulus Tepat Waktu, Kemampuan Menulis Karya Tulis Ilmiah, Ketersediaan Sumber Belajar, Kualitas Bimbingan Skripsi dan Lingkungan Teman Sebaya berpengaruh positif terhadap Penyelesaian Skripsi baik secara parsial maupun secara bersama-sama. Ditunjukkan dengan nilai $r_{\text {hitung }}$ secara urut yaitu sebesar 0,$534 ; 0,334 ; 0,239 ; 0,230$; dan 0,214 dengan nilai siginifikan setiap variabelnya $<5 \%$. Nilai $R_{\text {hitung }}$ sebesar 0,54 dan nilai $F_{\text {hitung }}(9,267)$ $>F_{\text {tabel }}(2,30)$
\end{abstract}

Kata kunci: Skripsi, Motivasi Lulus Tepat Waktu, Kemampuan Menulis Karya Tulis Ilmiah, Ketersediaan Sumber Belajar, Kualitas Bimbingan Skripsi, dan Lingkungan Teman Sebaya

\begin{abstract}
This study aims to investigate the effects of motivation to graduate on time, ability to write scientific papers, availability of learning resources, quality of undergraduate thesis guidance, and peer environment both partially and simultaneously on the completion of accounting education student's undergraduate thesis. This research is a comparative causal study. The research population comprised all students of accounting education batch 2011, Yogyakarta State University. The data were collected through questionnaire. They were analyzed by simple regression and multiple regression. The results of study show that motivation to graduate on time, ability to write scientific papers, availability of learning resources, quality of undergraduate thesis guidance, and peer environment both partially and simultaneously have a positive effect on the completion of the undergraduate thesis. It is indicated by the value of $r$ count in sequence as following: 0.534; 0.334; 0.239; 0.230; and 0.214 with significance value of each variable is $<5 \%$. The value of Rcount equal 0.54 and value of Fcount (9.267) >value of Ftabel (2.30).
\end{abstract}

Keywords: Undergraduate Thesis, Motivation to Graduate On Time, Ability to Write Scientific Papers, Availability of Learning Resources, Quality of Undergraduate Thesis Guidance, and Peer Environment. 


\section{PENDAHULUAN}

Pendidikan menjadi cerminan kualitas suatu negara karena mampu memberikan gambaran kualitas sumberdaya manusia di dalamnya. Pendidikan nasional itu sendiri bertujuan untuk mencerdaskan kehidupan bangsa dan mengembangkan manusia Indonesia seutuhnya, berbudi pekerti luhur, memiliki pengetahuan, dan keterampilan sebagaimana tertera dalam Undang-Undang Republik Indonesia Nomor 20 Tahun 2003 Bab 1 Ketentuan Umum Pasal 3 yang berbunyi "Pendidikan nasional berfungsi mengembangkan kemampuan dan membentuk watak serta peradaban bangsa yang bermartabat dalam rangka mencerdaskan kehidupan bangsa, bertujuan untuk berkembangnya potensi peserta didik agar menjadi manusia yang beriman dan bertakwa kepada Tuhan Yang Maha Esa, berakhlak mulia, sehat, berilmu, cakap, kreatif, mandiri, dan menjadi warga negara yang demokratis serta bertanggung jawab". Untuk mewujudkan hal tersebut maka setiap lembaga pendidikan yang salah satu di antaranya adalah perguruan tinggi, dituntut untuk bisa menjaga kualitas proses pembelajaran dan meningkatkan kualitas lulusannya.

Universitas Negeri Yogyakarta (UNY) merupakan salah satu contoh lembaga pendidikan tinggi yang juga berupaya mewujudkan tujuan pendidikan nasional tersebut, sebagaimana tertuang dalam visinya yaitu "Pada tahun 2025 UNY menjadi universitas kependidikan kelas dunia berlandaskan ketaqwaan, kemandirian, dan kecendekiaan" (UNY, 2013)

Menurut Ibnu dan Yoga (2013), indikator keberhasilan pencapaian visi tersebut di antaranya adalah adanya peningkatan indeks prestasi kelulusan, penurunan lama studi, dan peningkatan kecepatan memperoleh pekerjaan. Namun dalam pelaksanaannya, indikator pencapaian visi UNY pada aspek penurunan lama studi masih mengalami permasalahan. Hal ini dikarenakan masih banyaknya mahasiswa UNY yang mengalami kesulitan dalam menyelesaikan tugas akhir skripsi.

Hasil wawancara peneliti pada hari Rabu, 15 April 2015 menyebutkan bahwa dari 130 Mahasiswa Pendidikan Akuntansi FE UNY angkatan 2011 yang sudah dinyatakan lulus sampai dengan tanggal 15 April 2015 adalah sebanyak 41 mahasiswa atau sebesar 31,54\% sedangkan Mahasiswa Pendidikan Akuntansi FE UNY angkatan 2011 yang masih dalam proses Penyelesaian Tugas Akhir Skripsi adalah sebanyak 89 mahasiswa atau sebesar $68,46 \%$. Wawancara ini dilakukan kepada perwakilan Mahasiswa Pendidikan Akuntansi FE UNY angkatan 2011 yaitu perwakilan dari kelas A, Kelas B, dan Kelas I (Internasional).

\section{Tabel 1. Penyelesaian TAS Mahasiswa Pendidikan Akuntansi FE UNY 2011}

\begin{tabular}{|l|l|r|}
\hline No & Tahap Penyelesaian TAS & Jumlah \\
\hline 1 & Wisuda 3,5 Tahun & 12 \\
\hline 2 & Sudah Yudisium & 10 \\
\hline 3 & Selesai Ujian Skripsi & 19 \\
\hline 4 & Proses Laporan Penelitian & 46 \\
\hline 5 & Proses Proposal Penelitian & 39 \\
\hline 6 & Belum Mengajukan Judul & 4 \\
\hline \multicolumn{2}{|c|}{ Total Mahasiswa } & 130 \\
\hline
\end{tabular}

Sumber: Data Primer (15 April 2015)

Dengan angka yang cukup variatif tersebut menimbulkan sebuah pertanyaan, apa yang menjadi penghambat mahasiswa pendidikan Akuntansi FE UNY angkatan 2011 belum tuntas dalam Penyelesaian tugas akhir skripsinya? Padahal masa studi normal tinggal dua bulan lagi yaitu Juni 2015. Dari hasil wawancara, didapati informasi bahwa beberapa alasan belum selesainya tugas akhir skripsi mereka di antaranya adalah masih mengulang mata kuliah, kurangnya motivasi, rasa malas, lingkungan yang tidak mendukung baik lingkungan fisik seperti kondisi kos/rumah untuk segera menyelesaikan skripsinya maupun lingkungan sosial seperti teman, tidak sesuainya judul skripsi dengan minat/keinginan mahasiswa, tidak cocok 
dengan dosen pembimbing, sulitnya menemui dosen pembimbing, sulitnya menemukan sumber belajar yang sesuai dengan teori yang dibutuhkan, kurangnya kemampuan untuk mengelola kata saat menulis skripsi, ketidakpahaman mengenai karya tulis ilmiah, dan kesibukan mahasiswa itu sendiri seperti merawat keluarga yang sakit, kerja, dan organisasi.

Berdasarkan latar belakang di atas, maka penelitipun bermaksud untuk melakukan penelitian dengan judul "Faktor-Faktor yang Mempengaruhi Penyelesaian Tugas Akhir Skripsi (TAS) Mahasiswa Program Studi Pendidikan Akuntansi Fakultas Ekonomi Universitas Negeri Yogyakarta Angkatan 2011". Penelitian ini bertujuan untuk mengetahui faktor-faktor yang dapat mempengaruhi penyelesaian tugas akhir skripsi mahasiswa pendidikan akuntansi FE UNY 2011 yaitu berfokus pada faktor Motivasi Lulus Tepat Waktu, Kemampuan Menulis Karya Tulis Ilmiah, Ketersediaan Sumber Belajar, Kualitas Bimbingan Skripsi, dan Lingkungan Teman Sebaya yang di mana kesemua faktor ini merupakan representatif dari permasalahan yang diungkapkan di atas. Adapun manfaat dan kegunaan yang diharapkan dari penelitian ini adalah untuk memberikan informasi, masukan, dan referensi kepada Mahasiswa, Dosen, Jurusan, Pimpinan UNY dan unsur pembantu pimpinan di bidang akademik berkaitan faktor-faktor yang mempengaruhi penyelesaian tugas akhir skripsi guna melakukan perbaikan dan peningkatan mutu pendidikan yang lebih baik.

\section{METODE PENELITIAN}

\section{Jenis Penelitian}

Penelitian ini merupakan jenis penelitian kausal komparatif dan dengan pendekatan kuantitatif.

\section{Waktu dan Tempat Penelitian}

Penelitian ini dilakukan pada bulan Juli 2015 sampai Januari 2016 bertempat di Fakultas Ekonomi UNY.

\section{Target/Subjek Penelitian}

Populasi dalam penelitian ini adalah Mahasiswa Pendidikan Akuntansi Fakultas Ekonomi Universitas Negeri Yogyakarta Angkatan 2011 berjumlah 130 mahasiswa dan terdiri dari 3 kelas yaitu kelas A, kelas B, dan Kelas Internasional (I). Dalam penelitian ini, semua anggota populasi menjadi responden dalam pengambilan data, dimana teknik pengumpulan datanya adalah dengan menggunakan teknik sensus.

\section{Prosedur}

Penelitian ini dilaksanakan dengan empat tahap yaitu (1) pengumpulan data, tabulasi data, (3) analisis data, dan (4) penarikan kesimpulan dan saran.

\section{Data, Intrumen, dan Teknik Pengumpulan} a). Data

Data dalam penelitian ini adalah data berkenaan dengan faktor-faktor penyelesaian tugas akhir skripsi. Teknik pengumpulan data yang digunakan yaitu menggunakan angket atau kuesioner. Kuesioner dibagikan kepada mahasiswa Pendidikan Akuntansi FE UNY angkatan 2011 melalui google drive dan secara langsung di FE UNY.

b). Instrumen

Instrumen penelitian yang digunakan adalah angket tertutup, yaitu angket yang telah dilengkapi dengan alternatif jawaban dan responden bisa langsung memilih salah satu jawaban yang disediakan. Peneliti menggunakan skala bertingkat dengan empat alternatif jawaban yaitu sangat setuju, setuju, tidak setuju, dan sangat tidak setuju.

Untuk alternatif jawaban yang bersifat positif diberi skor berturut-turut 4, 3, 2, 1 dan untuk alternatif jawaban yang bersifat negatif diberi skor berturut-turut 1, 2, 3, 4 sedangkan untuk angket mengenai pencapaian Penyelesaian Tugas Akhir Skripsi (Y), responden diminta untuk mencentang pada tahapan mana tugas akhir skripsinya. Skor yang diberikan pada setiap tahapan TAS yang dikerjakan adalah antara 1 sampai 10.

Indikator yang digunakan untuk mengungkapkan data mengenai Motivasi 
Lulus Tepat Waktu (X) diadaposi dari pendapat Iskandar (2009) dan Sardimnan (2009) yaitu mahasiswa memiliki (1) Hasrat dan keinginan yang tinggi untuk lulus tepat waktu, (2) Harapan dan cita-cita, (3) Rasa kebutuhan fisiologis dan penghargaan terhadap pencapaian skripsi, dan (4) Ulet serta tekun dalam menyelesaikan tugas akhir skripsi. Kemudian untuk data mengenai Kemampuan Menulis Karya Tulis Ilmiah (X2) indikatornya meliputi (1) Pengetahuan dan wawasan tentang karya tulis ilmiah, (2) Pengalaman dan rutinitas menulis, (3) Kesesuaian judul dengan isi, (4) Gagasan yang dituangkan, (5) Pilihan kata (Diksi), (6) Tanda baca dan ejaan yang digunakan. Indikator Kemampuan Menulis Karya Tulis Ilmiah ini merujuk kepada pendapat Siti Maslakhah dkk (2011) dan Yulia, Nursyamsiar, dan Siti Halidjah (2013).

Ketersediaan Sumber Belajar (X3) diungkapkan dengan menggunakan indikator yang merujuk kepada pendapat Dewi Agustina (2014) dan Tata Sutabri (2005) yaitu (1) Ekonomis, (2) Mudah diperoleh, (3) Relevan, (4) Akura, dan (5) Aktual. Selanjutnya untuk data mengenai Kualitas Bimbingan Skripsi (X4) Indikatornya meliputi: (1) Dosen pembimbing melakukan tugasnya sesuai dengan pendidikan, pengalaman, dan kemampuannya, (2) Kuantitas dan kontinuitas bimbingan skripsi, (3) Program bimbingan yang sesuai dengan kebutuhan, (4) Situasi dan kondisi saat bimbingan, (5) Metode dan teknik bimbingan, (6) Peralatan dan perlengkapan yang digunakan dalam bimbingan skripsi. Indikator Kualitas Bimbingan Skripsi ini diadopsi dari pendapat TIM Dosen PBB FIP (2000) berkenaan dengan konseling dan bimbingan belajar.

Data mengenai Lingkungan Teman Sebaya (5) diungkap dengan indikator yang merujuk kepada pendapat Santrock (2012) dan Umar (2005) yaitu (1) Interaksi sosial yang dilakukan, (2) Tempat berbagi pengetahuan, (3) Berbagi cerita dan saling memotivasi, (4) Partner belajar dan standar keberhasilan belajar sedangkan untuk ketercapaian atau tahapan dalam Penyelesaian Tugas Akhir Skripsi (Y) diungkap berdasarkan panduan Tugas Akhir Skripsi (Tim Dosen Pendidikan Akuntansi, 2007) yaitu dalam (1) tahap penentuan judul skripsi, (2) tahap menyusun draf proposal skripsi, (3) judul skripsi yang diajukan telah disetujui, (4) tahap menyusun proposal skripsi, (5) sudah atau akan seminar proposal skripsi, (6) tahap penelitian dan pengambilan data, (7) tahap menyusun laporan hasil penelitian, (8) tahap persiapan ujian skripsi/beberapa hari kedepan akan ujian skripsi, (9) telah lulus ujian skripsi dan dalam perbaikan, dan (10) telah lulus ujian skripsi tanpa perbaikan atau sudah melakukan perbaikan.

Dalam penelitian ini, uji coba instrumen dilakukan dengan uji coba terpakai dimana pengujian instrumen dilakukan pada 30 Mahasiswa Pendidikan Akuntansi FE UNY angkatan 2011 yang juga digunakan ketika menguji hipotesis. Uji persyaratan instrumen penelitian yang digunakan yaitu uji validitas dan reabilitas.

Pengujian validitas menggunakan rumus korelasi Product Moment, adapun rumusnya adalah sebagai berikut:

$$
r_{x y}=\frac{N \sum X Y-\left(\sum X\right)\left(\sum Y\right)}{\sqrt{\left.\left\{N \sum X^{2}-\left(\sum X\right)^{2}\right) / N \sum Y^{2}-\left(\sum Y\right)^{2}\right\}}}
$$

Keterangan:

$\mathrm{r}_{\mathrm{xy}} \quad$ : Koefisien korelasi antara $\mathrm{X}$ dan $\mathrm{Y}$

$\mathrm{N}$ : Jumlah responden

$\sum X Y$ : Jumlah perkalian skor butir X \& Y

$\sum X \quad$ : Jumlah skor butir $X$

$\sum \mathrm{Y} \quad$ : Jumlah skor total $\mathrm{Y}$

$\sum X^{2}$ : Jumlah kuadrat dari skor butir $\mathrm{X}$

$\sum \mathrm{Y}^{2}$ : Jumlah kuadrat dari skor total $\mathrm{Y}$

(Suharsimi Arikunto, 2013: 87)

Kriteria pengambilan keputusan untuk menentukan valid jika harga $\mathrm{r}_{\text {hitung sama }}$ dengan atau lebih besar daripada harga $r_{\text {tabel }}$ pada taraf signifikansi 5\%. Jika harga $\mathrm{r}_{\text {hitung }}$ yang diperoleh lebih kecil dari $r_{\text {tabel }}$ pada taraf signifikan 5\% maka butir yang dimaksud tidak valid. Dari hasil analisis validitas instrumen diketahui nilai korelasi antara skor item dan skor total. Nilai tersebut kemudian 
dibandingkan dengan nilai $r_{\text {tabel }}$ pada taraf signifikansi 5\% dengan jumlah data (n) 30 yaitu sebesar 0,361 .

Adapun ringkasan hasil uji validitas instrumen dari lima variabel tersebut (X1, $\mathrm{X} 2, \mathrm{X} 3, \mathrm{X} 4$, dan X5) dapat dilihat pada tabel berikut ini:

Tabel 2. Ringkasan Hasil Uji Validitas Instrumen

\begin{tabular}{|l|c|c|c|c|}
\hline Var. & $\begin{array}{c}\text { Jum. } \\
\text { Item }\end{array}$ & $\begin{array}{l}\text { Item } \\
\text { Tidak } \\
\text { valid }\end{array}$ & $\begin{array}{l}\text { Jum. } \\
\text { Item } \\
\text { Tidak } \\
\text { Valid }\end{array}$ & $\begin{array}{l}\text { Jum. } \\
\text { Item } \\
\text { Digunaka } \\
\text { n }\end{array}$ \\
\hline X1 & 12 & - & 0 & 12 \\
\hline X2 & 18 & 4,11 & 2 & 16 \\
\hline X3 & 15 & $\begin{array}{c}1,3, \\
11,12\end{array}$ & 4 & 11 \\
\hline X4 & 17 & 15 & 1 & 16 \\
\hline X5 & 12 & 2 & 1 & 11 \\
\hline Jum. & $\mathbf{7 4}$ & - & $\mathbf{8}$ & $\mathbf{6 6}$ \\
\hline
\end{tabular}

Sumber : Data primer yang diolah.

Uji reliabilitas dalam penelitian ini menggunakan rumus koefisien alpha, yaitu:

$$
r_{11}=\left[\frac{k}{k-1}\right]\left[1-\frac{\sum \alpha b^{2}}{\sigma^{2} \mathrm{t}}\right]
$$

Keterangan:

$\mathrm{r}_{11} \quad$ : Reliabilitas instrumen

$\mathrm{k} \quad$ : Banyaknya butir pertanyaan

$\sum \mathrm{ob}^{2} \quad$ : Jumlah varians butir

$\mathrm{O}^{2} \mathrm{t} \quad$ : Varians total

(Suharsimi Arikunto, 2013: 122).

Jika koefisien alpha lebih besar dari $\mathrm{r}_{\text {tabel }}$ dengan taraf signifikasi 5\%, maka kuisioner tersebut dinyatakan reliabel sebaliknya jika koefisien alpha lebih kecil dari $\mathrm{r}_{\text {tabel }}$ dengan taraf siginifikansi 5\% maka kuesioner dinyatakan tidak reliabel. Untuk menginterpretasi hasil uji reliabilitas, maka digunakan pedoman sebagai berikut:

Tabel 3. Pedoman Interpretasi Koefisien Korelasi

\begin{tabular}{|c|c|}
\hline Interval koefisien & Tingkat hubungan \\
\hline $0,00-0,199$ & Sangat rendah \\
\hline $0,20-0,399$ & Rendah \\
\hline $0,40-0,599$ & Sedang \\
\hline $0,60-0,799$ & Kuat \\
\hline $0,80-1,000$ & Sangat kuat \\
\hline
\end{tabular}

(Sugiyono, 2010: 231).
Hasil uji reliabilitas instrumen dirangkum dalam tabel berikut:

Tabel 4. Ringkasan Hasil Uji Reliabilitas Instrumen

\begin{tabular}{|c|c|c|}
\hline Variabel & $\mathbf{R}_{\mathbf{1 1}}$ & Intepretasi \\
\hline $\mathrm{X} 1$ & 0,756 & Kuat \\
\hline $\mathrm{X} 2$ & 0,748 & Kuat \\
\hline $\mathrm{X} 3$ & 0,744 & Kuat \\
\hline $\mathrm{X} 4$ & 0,740 & Kuat \\
\hline $\mathrm{X} 5$ & 0,756 & Kuat \\
\hline
\end{tabular}

Sumber: Data primer yang diolah

c). Teknik Analisis Data

Teknik analisis data yang digunakan adalah teknik analisis regresi sederhana dan regresi ganda dengan melakukan uji prasyarat terlebih dahulu yaitu:

1) Uji Linieritas

Adapun rumusnya adalah sebagai berikut: $\mathrm{F}_{\text {reg }}=\frac{\text { RKreg }}{\text { RKres }}$

Keterangan:

$\mathrm{F}_{\text {reg }} \quad=$ Harga bilangan $\mathrm{F}$ garis regresi.

$\mathrm{RK}_{\text {reg }}=$ Rerata kuadrat garis regresi

$\mathrm{RK}_{\text {res }}=$ Rerata kuadrat residu.

(Sutrisno Hadi, 2004: 13)

Selanjutnya $F_{\text {hitung }}$ dikonsultasikan dengan $F_{\text {tabel }}$ pada taraf siginifikan 5\%. Apabila $F_{\text {hitung }}$ lebih kecil atau sama dengan $F_{\text {tabel }}$ maka terdapat hubungan linier antara variabel bebas terhadap variabel terikat. Jika $F_{\text {hitung }}$ lebih besar $F_{\text {tabel }}$ maka hubungan antara variabel bebas terhadap variabel terikat tidak linier.

Berdasarkan analisis data, maka diperoleh hasil pengujian linieritas seperti terangkum dalam tabel berikut ini:

Tabel 5. Rangkuman Hasil Uji Linieritas

\begin{tabular}{|c|c|c|c|c|c|c|}
\hline \multirow{2}{*}{$\begin{array}{c}\text { N } \\
\mathbf{0}\end{array}$} & $\begin{array}{c}\text { Kolera } \\
\text { si }\end{array}$ & Hit & $\begin{array}{c}\text { Ta } \\
\text { b }\end{array}$ & $\begin{array}{c}\text { Fev. } \\
\boldsymbol{m} \\
\text { Lini } \\
\text { erity }\end{array}$ & Sig & $\begin{array}{c}\text { Ke } \\
\mathbf{t}\end{array}$ \\
\hline 1 & $\mathrm{X}_{1} \rightarrow \mathrm{Y}$ & $\begin{array}{c}0,9 \\
53\end{array}$ & $\begin{array}{c}2,3 \\
0\end{array}$ & $\begin{array}{c}0,52 \\
9\end{array}$ & $\begin{array}{c}0,0 \\
00\end{array}$ & $\begin{array}{c}\text { Lin } \\
\text { ier }\end{array}$ \\
\hline
\end{tabular}




\begin{tabular}{|l|l|c|c|c|c|c|}
\hline \multirow{2}{*}{2} & $\mathrm{X}_{2} \rightarrow \mathrm{Y}$ & 1,2 & & 0,25 & 0,0 & \\
& & 18 & & 6 & 00 & \\
\hline 3 & $\mathrm{X}_{3} \rightarrow \mathrm{Y}$ & 0,8 & & 0,69 & 0,0 & \\
& & 02 & & 4 & 12 & \\
\cline { 1 - 3 } 2 & $\mathrm{X}_{4} \rightarrow \mathrm{Y}$ & 0,8 & 2,3 & 0,65 & 0,0 & Lin \\
& & 59 & 0 & 7 & 16 & ier \\
\cline { 1 - 2 } 5 & $\mathrm{X}_{5} \rightarrow \mathrm{Y}$ & 1,6 & & 0,06 & 0,0 & \\
& & 49 & & 7 & 17 & \\
\hline
\end{tabular}

Sumber: Data primer yang diolah

\section{2) Uji Multikoliniertas}

Kriteria menentukan ada tidaknya multikolinearitas antarvariabel bebas yaitu mengalami multikolinieritas jika $\alpha_{\text {hitung }}$ $<\alpha$ dengan $\mathrm{VIF}_{\text {hitung }}>\mathrm{VIF}$ dan tidak mengalami multikolinieritas jika á hitung $>\alpha$ dengan $\mathrm{VIF}_{\text {hitung }}<\mathrm{VIF}$ (Danang Sunyoto, 2007: 90). Hasil uji multikolinieritas secara ringkas disajikan dalam tabel berikut:

Tabel 6. Rangkuman Hasil Uji Multikolinieritas

\begin{tabular}{|c|c|c|c|}
\hline Var. & Tolerance & VIF & Ket \\
\hline $\mathrm{X} 1$ & 0,639 & 1,565 & \multirow{5}{*}{$\begin{array}{c}\text { Tidak } \\
\text { Terjadi } \\
\text { Multiko } \\
\text { Linieritas }\end{array}$} \\
\hline $\mathrm{X} 2$ & 0,682 & 1,466 & \\
\hline X3 & 0,902 & 1,109 & \\
\hline $\mathrm{X} 4$ & 0,761 & 1,313 & \\
\hline $\mathrm{X} 5$ & 0,797 & 1,254 & \\
\hline
\end{tabular}

Sumber: Data Primer yang diolah

3) Uji Heteroskedastisitas

Analisis uji asumsi heteroskedastisitas dilakukan dengan uji glejser. Dimana dasar pengambilan keputasan (Sahid Raharjo, 2013) adalah sebagai berikut:

(a) Tidak terjadi heteroskedastisitas, jika nila thitung lebih kecil dari tabel dan nilai signifikansi lebih besar dari 0,05.

(b) Terjadi heteroskedastisitas, jika nila $t_{\text {hitung }}$ lebih besar dari $t_{\text {tabel }}$ dan nilai signifikansi lebih kecil dari 0,05.

Hasil uji heteroskedastisitas secara ringkas dapat dilihat dalam tabel berikut:
Tabel 7. Ringkasan Hasil Uji Heteroskedastisitas

\begin{tabular}{|c|c|c|c|}
\hline Var. & thitung & Sig & Keterangan \\
\hline $\mathrm{X}_{1}$ & $\begin{array}{c}- \\
3,635 \\
\end{array}$ & 0,000 & $\begin{array}{c}\text { Tidak terjadi } \\
\text { heteroskedastisitas* }\end{array}$ \\
\hline$X_{2}$ & $\begin{array}{c}- \\
1,390\end{array}$ & 0,167 & \multirow{4}{*}{$\begin{array}{c}\text { Tidak terjadi } \\
\text { heteroskedastisitas }\end{array}$} \\
\hline$X_{3}$ & 0,067 & 0,947 & \\
\hline $\mathrm{X}_{4}$ & 0,394 & 0,695 & \\
\hline $\mathrm{X}_{5}$ & 0,066 & 0,948 & \\
\hline
\end{tabular}

*tidak terjadi heteroskedastisitas dengan catatan nilai signifikan lebih dari 5\%

Sumber: Data primer yang diolah

\section{HASIL PENELITIAN DAN PEMBAHASAN}

Populasi dalam penelitian ini berjumlah 130 Mahasiswa akan tetapi dalam pengumpulan data tersebut, yang terkumpul adalah sebanyak 114 Mahasiswa sedangkan 16 Mahasiswa lainnya belum bisa diambil dikarenakan beberapa sebab seperti meninggal dunia (1), di daerah 3T (2), berhenti (2), pindah kampus (1), tidak bisa dihubungi (7), \& tidak memberi respon (3).

Pengujian hipotesis dalam penelitian ini digunakan untuk menguji apakah variabel bebas berpengaruh terhadap variabel terikat. Uji hipotesis pertama, kedua, ketiga, keempat, dan kelima menggunakan analisis regresi sederhana sedangkan uji hipotesis keenam menggunakan analisis regresi ganda.

Hasil penelitian mengenai pengaruh Motivasi Lulus Tepat Waktu (X1), Kemampuan Menulis Karya Tulis Ilmiah (X2), Ketersediaan Sumber Belajar (X3), Kualitas Bimbingan Skripsi (X4), dan Lingkungan Teman Sebaya (X5) terhadap Penyelesaian Tugas Akhir Skripsi (Y) mahasiswa Pendidikan Akuntansi Fakultas Ekonomi Universitas Negeri Yogyakarta angkatan 2011 dapat dilihat pada tabel di bawah ini: 
Tabel 8. Rangkuman Hasil Analisis Regresi Sederhana (X1, X2, X3, $\mathrm{X} 4, \mathrm{X} 5$ - Y)

\begin{tabular}{|c|c|c|c|c|c|c|c|}
\hline \multirow[b]{2}{*}{ Var. } & \multirow[b]{2}{*}{$\mathbf{r}$} & \multirow[b]{2}{*}{$\mathbf{r}^{2}$} & \multirow[b]{2}{*}{$\begin{array}{c}\mathbf{t} \\
\text { hit }\end{array}$} & \multirow[b]{2}{*}{$\overline{\vec{\theta}}$} & \multirow[b]{2}{*}{$\begin{array}{c}\text { Koe } \\
\text { f }\end{array}$} & \multirow[b]{2}{*}{$\begin{array}{c}\text { Kon } \\
\text { s }\end{array}$} & \multirow[b]{2}{*}{ Sig } \\
\hline & & & & & & & \\
\hline $\begin{array}{c}X \\
1\end{array}$ & 0,534 & $\begin{array}{c}0,2 \\
85\end{array}$ & $\begin{array}{c}6,6 \\
84\end{array}$ & \multirow{5}{*}{$\stackrel{\infty}{\infty}$} & $\begin{array}{c}0,19 \\
3\end{array}$ & $\begin{array}{c}1,53 \\
0\end{array}$ & $\begin{array}{c}0,00 \\
0\end{array}$ \\
\hline $\begin{array}{c}X \\
2\end{array}$ & 0,334 & $\begin{array}{l}0,1 \\
11\end{array}$ & $\begin{array}{l}3,7 \\
45\end{array}$ & & $\begin{array}{c}0,13 \\
5\end{array}$ & $\begin{array}{c}2,69 \\
5\end{array}$ & $\begin{array}{c}0,00 \\
0\end{array}$ \\
\hline & 0,239 & $\begin{array}{l}0,0 \\
57\end{array}$ & $\begin{array}{l}2,6 \\
04\end{array}$ & & $\begin{array}{c}0,10 \\
4\end{array}$ & $\begin{array}{c}5,39 \\
7\end{array}$ & $\begin{array}{c}0,01 \\
0\end{array}$ \\
\hline $\begin{array}{r}X \\
4 \\
\end{array}$ & 0,230 & $\begin{array}{l}0,0 \\
53 \\
\end{array}$ & $\begin{array}{l}2,4 \\
97 \\
\end{array}$ & & $\begin{array}{c}0,08 \\
0\end{array}$ & $\begin{array}{c}4,92 \\
7\end{array}$ & $\begin{array}{c}0,01 \\
4\end{array}$ \\
\hline $\begin{array}{l}X \\
5\end{array}$ & 0,214 & $\begin{array}{l}0,0 \\
46\end{array}$ & $\begin{array}{l}2,3 \\
17\end{array}$ & & $\begin{array}{c}0,09 \\
1\end{array}$ & $\begin{array}{c}5,53 \\
6\end{array}$ & $\begin{array}{c}0,02 \\
2\end{array}$ \\
\hline
\end{tabular}

Sumber: Data primer yang diolah

Dari tabel hasil analisis regresi sederhana dan analisis regresi ganda atas uji hipotesis di atas maka dapat ditarik kesimpulan bahwa:

1. Harga koefisien korelasi (rx1y) sebesar 0,534 dan koefisien determinasi $\left(\mathrm{r}^{2} \mathrm{x} 1 \mathrm{y}\right)$ sebesar 0,285 , harga $t_{\text {hitung }}$ lebih besar dari $t_{\text {tabel }}$ pada taraf signifikansi $5 \%$ yaitu sebesar 6,684 $(6,684>1,981)$ dengan jumlah responden sebanyak 114 mahasiswa. Persamaan regresi sederhana yang diperoleh adalah $\mathrm{Y}=0,193 \mathrm{X}_{1}+$ 1,530 yang berarti apabila Motivasi Lulus Tepat Waktu $\left(\mathrm{X}_{1}\right)$ meningkat 1 poin, maka Penyelesaian Tugas Akhir Skripsi (Y) akan meningkat 0,193 poin sehingga disimpulkan bahwa terdapat pengaruh positif dan signifikan Motivasi Lulus Tepat Waktu terhadap Penyelesaian Tugas Akhir Skripsi (TAS) Mahasiswa Program Studi Pendidikan Akuntansi Fakultas Ekonomi Universitas Negeri Yogyakarta (FE UNY) angkatan 2011.

2. Harga koefisien korelasi (rx2y) sebesar 0,334 dan koefisien determinasi $\left(r^{2} \mathrm{x} 2 \mathrm{y}\right)$ sebesar 0,111, harga thitung lebih besar dari $t_{\text {tabel }}$ pada taraf signifikansi $5 \%$ yaitu $3,745(3,745>1,981)$ dengan jumlah responden sebanyak 114 mahasiswa. Persamaan regresi sederhana yang diperoleh adalah $\mathrm{Y}=0,135 \mathrm{X}_{2}+2,695$ yang berarti apabila Kemampuan Menulis Karya Tulis Ilmiah $\left(\mathrm{X}_{2}\right)$ meningkat 1 poin, maka Penyelesaian Tugas Akhir Skripsi (Y) akan meningkat 0,135 poin sehingga disimpulkan bahwa terdapat pengaruh positif dan signifikan Kemampuan Menulis Karya Tulis Ilmiah terhadap Penyelesaian Tugas Akhir Skripsi (TAS) Mahasiswa Program Studi Pendidikan Akuntansi FE UNY angkatan 2011.

3. Harga koefisien korelasi (rx3y) sebesar 0,239 dan koefisien determinasi $\left(\mathrm{r}^{2} \mathrm{x} 3 \mathrm{y}\right)$ sebesar 0,057, harga thitung lebih besar dari tabel pada taraf signifikansi 5\% yaitu 2,604 $(2,604>1,981)$ dengan jumlah responden sebanyak 114 mahasiswa. Persamaan regresi sederhana yang diperoleh adalah $\mathrm{Y}=0,104 \mathrm{X}_{3}+5,397$ yang berarti apabila Ketersediaan Sumber Belajar $\left(\mathrm{X}_{3}\right)$ meningkat 1 poin, maka Penyelesaian Tugas Akhir Skripsi (Y) akan meningkat 0,104 poin sehingga disimpulkan bahwa terdapat pengaruh positif dan signifikan Ketersediaan Sumber Belajar terhadap Penyelesaian Tugas Akhir Skripsi (TAS) Mahasiswa Program Studi Pendidikan Akuntansi FE UNY angkatan 2011.

4. Harga koefisien korelasi (rx4y) sebesar 0,230 dan koefisien determinasi $\left(\mathrm{r}^{2} \mathrm{x} 4 \mathrm{y}\right)$ sebesar 0,053, harga thitung lebih besar dari tabel pada taraf signifikansi 5\% yaitu 2,497 $(2,497>1,981)$ dengan jumlah responden sebanyak 114 siswa. Persamaan regresi sederhana yang diperoleh adalah $\mathrm{Y}=0,080 \mathrm{X}_{4}+4,927$ yang berarti apabila Kualitas Bimbingan Skripsi $\left(\mathrm{X}_{4}\right)$ meningkat 1 poin, maka Penyelesaian Tugas Akhir Skripsi (Y) akan meningkat 0,080 poin sehingga disimpulkan bahwa terdapat pengaruh positif dan signifikan Kualitas Bimbingan Skripsi terhadap Penyelesaian Tugas Akhir Skripsi (TAS) 
Mahasiswa Program Studi Pendidikan Akuntansi FE UNY angkatan 2011

5. Harga koefisien korelasi (rx5y) sebesar 0,214 dan koefisien determinasi ( $\left.\mathrm{r}^{2} \mathrm{x} 5 \mathrm{y}\right)$ sebesar 0,046, harga thitung lebih besar dari $t_{\text {tabel }}$ pada taraf signifikansi $5 \%$ yaitu $2,317(2,317>1,981)$ dengan jumlah responden sebanyak 114 mahasiswa. Persamaan regresi sederhana yang diperoleh adalah $\mathrm{Y}=0,091 \mathrm{X}_{5}+5,536$ yang berarti apabila Lingkungan Teman Sebaya $\left(\mathrm{X}_{5}\right)$ meningkat 1 poin, maka Penyelesaian Tugas Akhir Skripsi (Y) akan meningkat 0,091 poin sehingga disimpulkan bahwa terdapat pengaruh positif dan signifikan Lingkungan Teman Sebaya terhadap Penyelesaian Tugas Akhir Skripsi (TAS) Mahasiswa Program Studi Pendidikan Akuntansi FE UNY angkatan 2011.

Untuk hasil uji hipotesis keenam yaitu uji regresi ganda diperoleh data seperti sebagai berikut:

Tabel 9. Rangkuman Hasil Analisis Regresi Ganda

\begin{tabular}{|c|c|c|c|c|c|c|}
\hline Var. & $\mathbf{R}$ & $\mathbf{R}^{2}$ & $\begin{array}{c}\text { F } \\
\text { hit }\end{array}$ & $\begin{array}{l}\text { F } \\
\text { ta }\end{array}$ & Koef & $\begin{array}{c}\text { Kon } \\
\mathbf{S}\end{array}$ \\
\hline $\begin{array}{c}X \\
1\end{array}$ & \multirow{5}{*}{$\begin{array}{c}0,5 \\
48\end{array}$} & \multirow{5}{*}{$\begin{array}{c}0,3 \\
00\end{array}$} & \multirow{5}{*}{$\begin{array}{c}9,2 \\
67\end{array}$} & \multirow{5}{*}{$\begin{array}{l}2, \\
3 \\
0\end{array}$} & 0,168 & \multirow{5}{*}{-550} \\
\hline$X$ & & & & & 0,028 & \\
\hline$X$ & & & & & 0,044 & \\
\hline $\begin{array}{l}3 \\
X\end{array}$ & & & & & 0,007 & \\
\hline $\begin{array}{c}4 \\
X \\
5\end{array}$ & & & & & 0,002 & \\
\hline
\end{tabular}

Sumber: Data primer yang diolah

Harga koefisien korelasi ganda $\operatorname{Rx}(1,2,3,4,5) y$ sebesar 0,548 dan koefisien determinasi ganda $\mathrm{R}^{2} \mathrm{x}(1,2,3,4,5) \mathrm{y}$ sebesar 0,300 , nilai $F_{\text {hitung }}$ lebih besar dari $F_{\text {tabel }}$ pada taraf signifikansi 5\% yaitu 9,267 (9,267> $2,30)$, dan diperoleh persamaan regresi ganda $\mathrm{Y}=0,168 \mathrm{X}_{1}+0,028 \mathrm{X}_{2}+0,044 \mathrm{X}_{3}+0,007 \mathrm{X}_{4}$ $+0,002 X_{5}-550$ sehingga dapat disimpulkan bahwa Terdapat pengaruh positif dan signifikan Motivasi Lulus Tepat Waktu, Kemampuan Menulis Karya Tulis Ilmiah, Ketersediaan Sumber Belajar, dan Lingkungan Teman Sebaya secara bersamasama terhadap Penyelesaian Tugas Akhir Skripsi (TAS) Mahasiswa Program Studi Pendidikan Akuntansi FE UNY angkatan 2011.

\section{SIMPULAN DAN SARAN Simpulan}

Hasil penelitian ini menunjukkan bahwa terdapat pengaruh positif: (1) Motivasi Lulus Tepat Waktu terhadap Penyelesaian Tugas Akhir Skripsi yang ditunjukkan dengan nilai $\mathrm{r}_{\text {hitung }}$ sebesar 0,534; dan nilai siginifikan 0,000 (2) Kemampuan Menulis Karya Tulis Ilmiah terhadap Penyelesaian Tugas Akhir Skripsi yang ditunjukkan dengan nilai $\mathrm{r}_{\text {hitung }}$ sebesar 0,334; dan nilai siginifikan 0,000 (3) Ketersediaan Sumber Belajar terhadap Penyelesaian Tugas Akhir Skripsi yang ditunjukkan dengan nilai $r_{\text {hitung }}$ sebesar 0,239 ; dan nilai siginifikan 0,010 (4) Kualitas Bimbingan Skripsi terhadap Penyelesaian Tugas Akhir Skripsi yang ditunjukkan dengan nilai $\mathrm{r}_{\text {hitung }}$ sebesar 0,230; dan nilai siginifikan 0,014 (5) Lingkungan Teman Sebaya terhadap Penyelesaian Tugas Akhir Skripsi yang ditunjukkan dengan nilai $\mathrm{r}_{\text {hitung }}$ sebesar 0,214 dan nilai siginifikan 0,022 dan (6) Motivasi Lulus tepat Waktu, Kemampuan Menulis Karya Tulis Ilmiah, Ketersediaan Sumber Belajar, Kualitas Bimbingan Skripsi, dan Lingkungan Teman Sebaya secara bersama-sama juga berpengaruh positif terhadap Penyelesaian Tugas Akhir Skripsi mahasiswa Pendidikan Akuntansi FE UNY angkatan 2011 yang ditunjukkan dengan nilai $\mathrm{R}_{\text {hitung }}$ sebesar 0,548 dan nilai $\mathrm{F}_{\text {hitung }}$ lebih besar dari $F_{\text {tabel }}$ yaitu 9,267 > 2,30.

\section{Saran}

a. Bagi mahasiswa, agar bisa (1) memiliki dan membangun motivasi yang besar untuk bisa lulus tepat waktu seperti memiliki motif/alasan yang kuat untuk segera lulus S1 dan menghindari hal-hal 
yang dapat menimbulkan rasa malas agar Motivasi Lulus Tetap Waktu tetap terjaga dengan baik seperti menghindari tidur yang berlebihan, terlalu banyak bermain games dan sosial media. (2) Belajar dan melatih diri untuk meningkatkan kemampuan menulis karya tulis ilmiah yang baik, dengan mengikuti kegiatan-kegiatan ilmiah seperti diskusi ilmiah, seminar, dan mencoba mengikuti lomba karya tulis ilmiah (3) Berusaha untuk mencari dan memanfaat fasilitas kampus yang sudah ada secara optimal seperti akses wifi kampus, perpustakaan, dan akses jurnal elektronik gratis yang ada. (4) Selalu memanfaatkan kesempatan bimbingan skripsi dengan baik, dan (5) Lebih selektif dalam memilih teman, mampu untuk mengkondisikan lingkungan sosial dan intensitas interaksi yang dilakukan.

b. Bagi Dosen, agar bisa memberikan pelayanan bimbingan skripsi yang lebih baik, bersedia untuk memberi waktu luang, arahan, solusi, dan motivasi kepada mahasiswa bimbingannya, serta diharapkan bisa memanajemen waktu dan prioritas pekerjaannya.

c. Bagi peneliti berikutnya, untuk meneliti lebih lanjut tentang faktor-faktor lain yang mempengaruhi Penyelesaian Tugas Akhir Skripsi seperti minat, tempat penelitian, subjek penelitian, administratif skripsi, keluarga, kakak kelas, organisasi, jenis penelitian, dan lainnya. Selain itu, perlu juga untuk memiliki patokan waktu dalam pengambilan data mengenai Penyelesaian Tugas Akhir Skripsi agar data yang diperoleh merupakan data yang ideal untuk mengukapkan pencapaian Penyelesaian Tugas Akhir Skripsi mahasiswa yang diteliti serta kontrol data yang didapat dari responden juga perlu untuk dilakukan agar persepsi data lebih berimbang.

\section{DAFTAR PUSTAKA}

Danang Sunyoto. (2007). Analisis Regresi dan Korelasi Bivariat. Yogyakarta: Amora books

Dewi Agustina. (2014). "Kompetensi Guru dalam Pemanfaatan Sumber Belajar Geografi SMA Negeri”. E-Joernal. Semarang: IKIP Veteran Semarang.

Ibnu Siswanto dan Yoga Guntur Sampurno. (2013). "Faktor-Faktor Penghambat Penyelesaian Tugas Akhir Skripsi Mahasiswa Pendidikan Teknik Otomotif FT UNY" E-Joernal. Yogyakarta: FT UNY.

Iskandar. (2009). Psikologi Pendidikan Sebuah Orientasi Baru. Jakarta: Gaung Persabda.

M. Irham dan Novan Ardy Wiyani. (2014). Psikologi Pendidikan. Yogyakarta: Ar-Ruzz Media

Nana Syaodih Sukmadinata. (2009). Landasan Psikologis Proses Pendidikan. Bandung: PT Remaja Rosdakarya.

Sahid Raharjo. 2013. "Uji Heteroskedastisitas dengan uji glejser dengan program spss". Diunduh tanggal 6 Desember 2015 dari http://www.konsistensi.com/2013/08/ uji-heteroskedastisitasdenganuji.html

Santorck, Jhon. (2009). Psikologi Pendidikan. (Ahli Bahasa: Diana Angelica). Edisi Tiga. Buku Satu. Jakarta: Selemba Humanika.

Sardiman A.M. (2009). Interaksi dan Motivasi Belajar Mengajar. Jakarta: PT Raja Grafindo Persada.

Siti Maslakhah dkk. (2011). Bahasa Indonesia: Panduan Menulis Karya Ilmiah. Yogyakarta: Kanwa Publisher.

Sugiyono. (2010). Stastistika untuk Penelitian. Bandung: Alfabeta.

Suharsimi Arikunto._(2013). Dasar- Dasar Evaluasi Pendidikan. Jakarta: Bumi Aksara. 
Sutrisno Hadi. (2004). Analisis Regresi. Yogyakarta: Adi Offset

Tata Sutabri (2005). Sistem Informasi Manajemen. Jakarta

Tim Dosen PBB FIP UNY. (2000). Bimbingan dan Konseling Sekolah Menengah. UNY: FIP

Tim Dosen Pendidikan Akuntansi FE UNY (2007). Pedoman Tugas Akhir Skripsi. Yogyakarta: FE UNY.

Umar Tirtahardjo La Sulo. (2005). Pengantar Pendidikan. Jakarta: Pusat Perbukuan Depdiknas dan Penerbit Rineka Cipta Undang-Undang Republik Indonesia Nomor 20 Tahun 2003 tentang Sistem Pendidikan Indonesia

UNY. (2013). Mengenal UNY Lebih Dekat: Panduan Universitas Negeri Yogyakarta. Yogykarta: UNY.

Yulia, Nursyamsiar, dan Siti Halidjah. (2013). "Peningkatan Kemampuan Menulis Karangan Narasi dengan Strategi Menulis Terbimbing di Kelas IV SD”. E-Joernal. FKIP Universitas Tanjungpura. 